\title{
Manner and Result in English Verb Roots*
}

\author{
Lei Qiu \\ School of Foreign Languages, Huaiyin Normal Univerisity, Huaian, China
}

\begin{abstract}
MRC) proposed by Rappaport Hovav and Levin (1998, 2010) holds that a verb root cannot lexicalize manner and result meaning components simultaneously at a time. It has generated much interest and controversy among researchers. In spite of much evidence for it, researchers have also put forward a variety of arguments against it. This paper reviews arguments against the MRC hypothesis, reexamines the data these counterarguments are based on and reveals that these arguments do not pose real challenge for the MRC hypothesis. Counterexample verbs which are proposed to entail both manner and result actually lexicalize only one, either manner or result, and manner and result are indeed meaning component lexicalized in verb roots rather than aspectual focus.
\end{abstract}

Index Terms - manner, result, verb roots, lexicalized meaning

\section{INTRODUCTION}

Verbal meaning complexity at the lexicon and syntax interface has long been an intriguing topic, which inspires linguists' investigation from various approaches. On the one hand, linguists adopting constructionist approach believe that the meaning of verbal roots may be built with no constraint on its complexity, and in particular the role of a verb is only to provide a coherent semantic frame that evokes "a generalized, possibly complex states or events that constitute a cultural unit". (Goldberg, 2010, p. 41) On the other hand, lexical semanticists hold verbs' ontological categorization constrains the complexity of verb meaning and the lexical property of a verb associated with its ontological type is important to determining or constraining its argument expressions. Regarding the controversy, an effective way to check the validity of these arguments is to follow one of these approaches making a hypothesis about the nature of the lexical meaning of verbs and the interaction between lexicon and syntax and then see whether the empirical data are consistent with the hypothesis. The manner/result complementarity hypothesis proposed by Rappaport Hovav and Levin (1998, 2010) is such a hypothesis which can be used to check the validity of the theoretical positions at the lexicon and syntax. Based on their observation of the meaning components lexicalized in ontologically different types of verbs and their distinct grammatical behaviors, Rappaport Hovav and Levin $(1998,2010)$ suggest a systematic lexical gap in verbal meaning which they call manner/result complementarity:

1) Manner/result complementarity: Manner and result meaning components are in complementary distribution: a verb may lexicalize only one.

(Levin and Rappaport Hovav, 2013, p. 50)

As the MRC hypothesis is claimed to be a general principal constraining the lexicalization patterns of the entire lexicon, it has generated much interest and controversy among researchers. In spite of much evidence for it, researchers have also put forward a variety of arguments against it. The counterarguments approach the issue mainly from two different angles. Some researchers (Beavers and Koontz-Garboden, 2012; Goldberg, 2010) focusing on the lexical entailments of verbs propose some counterexample verbs which seem to encode both meaning components simultaneously in English. Other researchers (Mateu and Acedo-Matellan, 2012; Rapoport, 2012) reject a verb root view of the MRC, i.e., whereas they admit there are linguistic phenomena corresponding to the MRC, they do not accept that it is held at the lexical level. Rather they either argue that it results from different syntactic configurations which verbs appear in or believe that it is reflected through the differences in aspectual focus.

The paper reviews these two main arguments against the MRC hypothesis, reexamines the data these counterarguments are based on and reveals that these arguments do not pose real challenge for the MRC hypothesis. Counterexample verbs which are proposed to entail both manner and result actually lexicalize only one, either manner or result, and manner and result are indeed meaning component lexicalized in verb roots rather than aspectual focus. The paper starts with a review of the lexical approach to lexicon and syntactic interface and the motivation for the MRC hypothesis. Then it moves forward to investigations of proposed counterexample verbs to the MRC and arguments against the MRC as a lexical constraint. A conclusion is reached in the final section.

\section{LEXICAL APPROACHES TO LEXICON AND SYNTAX INTERFACE AND MRC}

The MRC hypothesis has its roots in the theoretical orientation that the behavior of a verb, particularly its argument

\footnotetext{
${ }^{*}$ This research is supported by Jiangsu Philosophy and Social Sciences Fund for Colleges (No. 2018SJA1586)
} 
realization patterns, is largely determined by its meaning. Adopting predicate decomposition approach, Levin and Rappaport Hovav (1995) and Rappaport Hovav and Levin (1998, 2010) make distinction between structural and idiosyncratic meaning encoded in verbs. Only a small set of the information related to linguistic representation is included in their structured lexical representation. The lexical decomposition of a verb is made up of both aspects of meaning. While the idiosyncratic part is encoded in terms of constants, the structural part is encoded in terms of a small set of lexical-semantic templates formed via various combinations of basic eventive predicates such as ACT, CAUSE, BECOME, etc. and constants such as STATE, MANNER, THING, PLACE, INSTRUMENT, etc. The basic inventory of event structure templates are listed in (2).

2) Lexical Semantic Templates

a. $[x$ ACT $<$ MANNER $>$ ] (activity)

b. $[\mathrm{x}\langle\mathrm{STATE}>]$ (state)

c. $[$ BECOME $[\mathrm{x}<\mathrm{STATE}>]]$ (achievement)

d. [[x ACT <MANNER>] CAUSE [BECOME [y <STATE $>]]]$ (accomplishment)

e. [x CAUSE [BECOME [y <STATE $>]]$ (accomplishment)

(Rappaport Hovav and Levin, 1998, p. 108)

As manner and result roots belong to different ontological types and thus have distinct positions in event schema: a manner root can only be modifier of the primitive predicate ACT and a result root is the argument of the primitive predicate BECOME, as in (3a) and (3b). It is also proposed that a root has only one position in an event structure. Thus it is predicted that there will be no single verb involving an event structure associated with two distinct positions ruling out the formulations like (3c) and (3d) and then leads to the emergence of two natural classes of verbs: manner and result verbs.

3) a. $[x$ ACT<MANNER> $]$

b. [[x ACT] CAUSE [y BECOME $<$ RESULT $>]]$

c. $[[x$ ACT $<$ ROOT1 $>$ ] CAUSE [y BECOME $<$ ROOT2>]]

d. [[x ACT $<$ ROOT $>$ ] CAUSE [y BECOME $<$ ROOT $>$ ]]

The classification of verbs into manner or result type is also supported by independent semantic notions underlying the two types of verbs: manner and result verbs are associated non-scalar and scalar changes respectively in their lexical semantics. Drawing from studies of scale structure in lexical semantics (Kennedy, 2001; Kennedy and McNally, 2005) Rappaport Hovav and Levin (2010) propose a scale is 'a set of degrees - point or intervals indicating measurement values - on a particular dimension (e.g. height, temperature, cost), with an associated ordering relation'. A scalar change in an entity involves a change in the value of one of its scalar-valued attributes in a particular direction. They also emphasize that though all dynamic verbs involve change, result verbs differ from manner verbs fundamentally in involving scalar changes, as they lexically specify a scale which represents an attribute of their argument and a change in value of this attribute in a particular direction along the scale. For instance, as explained by Rappaport and Levin (2010) the verb warm describes a change associated with a scale on the dimension of temperature, and the scale is made up of values in an increasing order, so the argument it predicates of undergoes a measurable change from a lower temperature to a higher one and thus it is regarded as scalar change. In contrast, manner verbs lexicalize non-scalar changes which are complex and cannot be characterized by an ordered set of values of a single attribute. For example, the verb jog, also illustrated by Rappaport and Levin, involves a specific sequence and pattern of movements of legs, though different from the action of walk, but collectively these movements do not represent a change in the values of a single attribute and thus cannot be measured by a scale, so it involves non-scalar change.

\section{COUNTEREXAMPLE VERBS IN ENGLISH}

As noted by Husband (2011), the ultimate validity of the MRC rests on negative evidence. It is the lack of verbs which contain both meaning components that supports the hypothesis. An obvious way to falsify the MRC is to name counterexamples. One group of alleged counterexample verbs to the MRC are so-called manner of killing verbs proposed by Beavers and Koontz-Garboden (2012) in (4).

4) Manner of killing verbs: crucify, drown, electrocute, guillotine, hang

They develop a series of diagnostics for both a result and a manner component in a verb's meaning. Based on their tests, they claim these verbs encode both meaning components violating the MRC. As to result components, using result denial test 'but nothing is different about $X$ ', object deletion tests and restricted resultative tests, they compare these verbs with canonical manner and result verbs and point out that these manner of killing verbs entail at least some result. For example, they illustrate with result denial tests and point out that these verbs pattern with canonical result verbs such as break disallowing denial of result, distinct from canonical manner verbs such as sweep without result entailments.

5) a. Tracy swept the floor, but nothing is different about it.

b. * Shane just broke the vase, but noting is about it.

c. *Jane just drowned/hanged/crucified Joe, but nothing is different about him.

(Beavers and Koontz-Garboden, 2012, pp. 9-10)

Similarly, in object deletion tests, these verbs also show similar grammatical behaviors with result verbs such as 
shatter disallowing object deletion, different from manner verbs such as scrub, as illustrated in (6). These tests lead them to the conclusion that these verbs must entail result meaning components.

6) a. All last night, Kim scrub.

b. *All last night Kim shattered.

c. *All last night Shane drowned/crucified/electrocuted.

(Beavers and Koontz-Garboden, 2012, pp. 12-13)

Likewise, using selectional restriction tests on subjects, denial of action and complexity of action tests, they conclude that the manner component in these verbs is also truth-conditionally entailed. For instance, these manner of killing verbs place selectional restriction on their subjects, patterning with other canonical manner verbs such as scrub and wipe in (7).

7) a. The hammer broke/shattered the vase.

b. *The earthquake scrubbed/wiped the floor.

c. *The wind hang/crucify Jesus.

(Beavers and Koontz-Garboden, 2012, pp. 18-19)

In addition, based on denial of action tests these linguists also claim the manner component can be identified. Assuming causation is entailed in (8), they believe the ungrammatical status of the sentence is attributed to the contradiction between the entailed action in these verbs and the absence of action indicated in the context. Thus they summarize these verbs also lexicalize a manner component.

8) * The governor crucified the prisoner, but didn't move a muscle — rather, after taking office she failed to issue a pardon!

(Beavers and Koontz-Garboden, 2012, p. 22)

In the following part, I will also have a close look at these verbs to check whether they lexicalize both meaning components simultaneously. A careful reanalysis of the actual uses of these verbs and the linguistic tests used by Beavers and Koontz-Garboden indicate that these verbs encode result but not manner and thus are merely result verbs.

Before the analysis of the actual uses of these verbs, it should be noted that not all manner of killing verbs proposed by Beavers and Koontz-Garboden are relevant to the MRC (Rappaport Hovav, 2015). While the MRC is considered in terms of its role in construction of verb meaning and verbs are often regarded as the default lexical unit the MRC applies to, it should be noted that the MRC is a lexical generalization about what is encoded in roots, which according to Rappaport Hovav and Levin (2010, 2015), are minimal meaningful elements of verbal meaning, but not verbs. Depending on what kind of lexical inventories and morphosyntactic structures available in a language, the grammatical unit of root may or may not overlap with that of verb. For example, in English many verbs such as run and wipe are mono-morpheme and thus the MRC applies to these monomorphemic verbs directly. However, as also noted by Rappaport Hovav and Levin (2010), in languages where verbs are productively formed by stems and affixes, the MRC only holds of the roots, the minimal meaningful lexical units rather than verbs. Therefore, one needs to be very cautious when judging whether a verb violates the MRC, since even in languages in which mono-morphemic verbs are the norm of verbal construction, there may be verbs built on two or more morphemes or through morphological derivation. The apparent counterexamples electrocute and guillotine fall into this type. Obviously, electrocute is formed by combining the two morphemes, electro- and execute. guillotine is denominal verb and the complexity of its meaning results from the complexity of the meaning related to the artifact noun it is derived from and from a rule of semantic interpretation accompanying a morphological derivation (Kiparsky, 1997; Levin and Rappaport Hovav, 2015). Therefore, electrocute and guillotine do not strictly negate MRC and the focus of the following discussion will be the three verbs crucify, drown and hang.

As to the meaning component of result of these verbs, Beavers and Koontz-Garboden state explicitly that they believe it to be 'death', but they also argue that what result is encoded is not important, since their tests indicate these verbs at least entail some result. However, besides direct evidence for or against a lexical entailment of death in these verbs, it is also important to reveal the exact nature of result if they do entail this sense, because it will help to determine whether these verbs lexicalize an additional manner sense. First, contrary to Beavers and Koontz-Garboden's belief, it is shown that these verbs do not entail the meaning component of death. Researchers (Husband, 2011; Aldridge, 2012) notice that these verbs may be used in sentences where no death is entailed, as seen in (9). Though these verbs are conventionally associated with a result sense of death giving us a strong impression that these verbs always bring about death, conventional meaning is irrelevant to the present issue, and death is not their entailed meaning component.

9) a. Ruben Enaje...is noted for being crucified 26 times...he has been crucified every year since 1985 on Good Friday

b. A man hung himself by a belt in his closet... two days later he walked out of the hospital.

c. We did find some limited case studies of adults who drowned in cold water and who occasionally survived

(Aldridge, 2012, p. 8)

Then it leaves us to determine whether these verbs lexicalize other result components. Though death is not the entailed meaning component of these verbs, I agree with Beavers and Koontz-Garboden that these verbs do encode certain result. To be specific, I argue these verbs specify acquisition of a highly specific property denoted by the invariant component of meaning in the root. For example, the verb crucify must entail somebody's acquisition of a 
property "being hung up in a particular configuration". In fact, it is exactly the result the verb lexicalizes, namely, being nailed to a cross. Similarly, the verb drown entails an entity's acquisition of a property 'being submerged in an ambient substance'. (Rappaport Hovav, 2015) This is verified by the fact that though as discussed above inferred death sense may be absent in some uses of these verbs, the meaning component concerning the acquisition of this highly specific property is constant across all uses of these verbs. As can be seen in (10), in the uses of these verbs, the acquisition of a kind of highly specific property by a theme denoted in the root cannot be cancelled.

10) a. *The governor crucified the prisoner, but he was not nailed to a cross.

b. *The governor hanged the prisoner, but he was not dropped with a rope around his neck.

c. *The governor drowned the prisoner, but he was not submerged in an ambient liquid substance.

As these verbs do encode result component, it is no wonder that these verbs pass the tests developed by Beavers and Koontz-Garboden aiming to identify result component of meaning. For example, the result denial test 'nothing is different of $X^{\prime}$ just indicates there is certain result, these verbs obviously will be attested to pattern with canonical result verbs. The same is true for object deletion tests. Since these verbs specify the acquisition of a new property by a theme, as a structural argument of BECOME the theme must be syntactically realized in line with the argument realization rule proposed by Rappaport Hovav and Levin (1998).

Since these verbs do entail result, the remaining task is to show they do not encode manner; otherwise they would be counterexamples to the MRC. In fact, if the exact nature of result is clarified, it is not difficult to prove the manner is absent in their lexical meaning. As discussed above, if the result meaning of these verbs is acquisition of the highly specific property denoted by the root, then there is no other meaning component encoded in these verbs. For example, as the verb hang specifies the result as acquisition of a property of being dropped with a rope around one's neck, then that is all about the lexical meaning and there is no additional meaning component concerning manner.

However, Beavers and Koontz-Garboden claim these verbs must involve an action by the agent, because using a negligence situation to deny an action (action denial test) results in contradiction as illustrated in (9), repeated as (11) below.

11) *The governor crucified the prisoner, but didn't move a muscle — rather, after taking office she failed to issue a pardon!

(Beavers and Koontz-Garboden, 2012, p. 22)

I argue that this test cannot be used to identify an action by the agent; rather it only proves that the external argument 'the negligent governor' is not a proper causer for the result specified by these verbs. In other words, given the context of (11), a causative relation cannot be naturally constructed between the governor and the result that the prisoner was crucified. That's why (11) is contradictory. Note that Beavers and Koontz-Garboden assume with supporting context in (11) there is an entailed causation, but their assumption is not verified and even more seriously it is this assumption that makes them misidentify an action involved in these verbs. Neelman and van de Koot (2010) argue that for an external argument to be a proper causer of an event, the external argument must be identified as the crucial contributing factor (CCF). In addition, Neelman and van de Koot also point out that for some causative verbs the intentionality of an external argument is critical for deciding whether the external argument can be regarded as the CCF, though the action by the external argument is irrelevant. For example, the verb murder, though as a result verb not specifying manner or means, it only selects an external argument with intentionality to be the CCF, as seen in (12).

12) a. *The earthquake murdered the family.

b. *John murdered Mary by accident.

Verbs selecting external argument with intentionality to be CCF are incompatible with a causative relation resulting from negligence, since negligence is prototypically regarded as unintentional. However, as noted by Rappaport Hovav (2015) the transitive use of verbs electrocute and crucify in Beavers and Koontz-Garboden's example in particular predisposes the association of the verb with an external argument with intentionality, this is contradictory to the negligence situation. That's why (11) is unacceptable.

A more direct evidence for the absence of manner in these manner of killing verbs is that these verbs allow inanimate subject, as seen in (13)

13) a. Presumably one of [Basil] Clark's more imaginative underlings concocted the fiction that he had been buried up to his neck near the high tide point and left there for the rising sea to drown him.....finally the waters drowned him.

(Rappaport Hovav, 2015, p. 7)

b. Without realizing that the cord had become wrapped around her neck, Mary jumped from the bridge, and the cord snapped taut and hanged her.

(Aldridge, 2012, p.10)

More significantly, the verbs drown and hang also participate in unaccusative-causative alternation, as in (14), though it is observed that verbs which impose restrictions on external argument cannot be used in this way. This provides further evidence that these verbs do not specify any manner executed by an external argument.

14) a. The man drowned.

b. At that time you could hang for stealing.

To summarize, Beavers and Koontz-Garboden's claim that some manner-of-killing verbs also lexicalize manner is 
merely an illusion. These verbs do not necessarily involve an action by the agent, and rather they only require external arguments with intentionality in their causative uses. Instead of posing selectional restrictions on subjects, with proper context these verbs allow inanimate subjects. Some of them also participate in causative-unaccusative alternation. Therefore, it is clear from the discussion above that these manner-of-killing verbs only encode result but not manner, and they are result verbs.

Focusing on purported counterexamples to the MRC proposed by Beavers and Koontz-Garboden this section analyzes the actual uses of manner of killing and argues that these verbs lexicalize only result meaning component. Therefore, they do not pose real challenge for the MRC hypothesis.

\section{MRC AS A LEXICAL CONSTRAINT}

Other researchers admit that there are linguistic phenomena corresponding to the MRC, but they deny it as a principle operating in the lexicon. For example, Mateu and Acedo-Matellan (2012) argue the relevant linguistic phenomena corresponding to the MRC result from different syntactic configurations. Rapoport (2012) abandoning both the syntactic view of Mateu and Acedo-Matellan and a verb root view of Rappaport Hovav and Levin argues that what the MRC reflects is just a switch in aspectual focus. Focusing on the counterarguments from the two approaches, this section reexamines the empirical evidence corresponding to the MRC and argues semantic notions of manner and result based on verb root are well motivated.

Mateu and Acedo-Matellan (2012) propose a syntactic approach to the MRC. According to these linguists, verb roots are not inherently typed as manner or result and the conceptual components encoded in verbs are not constrained in its complexity. Roots can integrate into syntactic structure in any way. The precise meaning of the verb in a sentence is determined by how and where the root is integrated into the syntactic structure. The MRC results from different configurations roots are associated with. A result sense is read off if a root appears as the predicate of a small clause through incorporation and a manner sense is interpreted if a root is an adjunct of v. Since a root cannot possibly take two distinct positions in syntactic structure, the MRC follows.

Note that the lexicalist approach proposed by Rappaport Hovav and Levin $(1995,1998,2010)$ and the syntactic approach adopted by Mateu and Acedo-Matellan (2012) are not completely incompatible. They share at least two points. First, the two approaches have a consensus on the bipartite nature of meaning, i.e., verb meaning components are made up of two parts: the structural meaning and idiosyncratic meaning. They both recognize that it is the structural meaning of a verb that affects a verb's argument realization patterns and other grammatical behaviors. Second, as to the MRC, they both adopt a verb root view that a root has only one position in certain structure ruling out the possibility that a verb root is associated with two positions simultaneously.

However, the two approaches also contrast with each other concerning the nature of the structural meaning. Rappaport Hovav and Levin consider the structural meaning to be represented as event structure, which is determined by the semantics of the predicate, whereas Mateu and Acedo-Matellan argue the structural meaning is not determined by the lexical predicate but by syntactic construction. In fact, it is just their different theoretical positions as to the nature of structural meaning that makes them to interpret the linguistic phenomena corresponding to the MRC differently. The evidence to support the syntactic approach is that the most prototypical result verb break can be interpreted as either manner or result sense when it takes different positions in syntactic structure, as in (15)

15) a. He broke into the room. [vP [v $\sqrt{ } \mathrm{BREAK} v]$ [SC [DP he] [into the room]]]

b. The glass broke. [vP v [SC [DP the glass] [ $\sqrt{\mathrm{BREAK}}]]]$

(Mateu and Acedo-Matellan, 2012, p. 6)

Nonetheless, Rappaport Hovav (2015) argues that the meaning component of manner should be differentiated from the relational notion of manner, as in principle both manner and result roots may be used as event modifier representing relational manner as in (46a). In this case, though the root is used to modify the whole event, its truth conditional content/ontological type is still that of result. She further explains that a verb root sometimes can be used to modify an event type which it is not prototypically associated with. An example Rappaport Hovav provides is the way construction which describes moving along a path in a particular manner. It has been observed by linguists (Goldberg 1995, Jakendoff 1997, among others) that verbs in this construction in their unmarked uses do not normally select the way complement and they are often manner verbs, but sometimes result verbs can also be used, as in (16)

16) The woman's 13-year-old, who broke his way out to safety, says he woke up to find his whole house on fire.

(Rappaport Hovav, 2015, p. 3)

As to this case, though the result verb break is used to modify a transitional motion which is different from the change encoded in its lexical meaning, the truth conditional content or the ontological type remains unchanged, namely, a result one.

In addition, concerning the problems that the syntactic approaches to argument realization face in general, Kiparsky (1997) points out that even a pure syntactic structure has to make crucial reference to conceptual knowledge and thus requires a semantic representation of the predicate. For instance, in Mateu and Acedo-Matellan's analysis of the manner-of-killing verb guillotine, they argue the syntactic argument structure of the verb in (17a) corresponds to its use 
as a causative predicate of change-of-state as in (17b). In this case the root is the complement of an abstract P element that expresses 'Terminal Coincidence Relation'. 'However, they also explain that structurally nothing prevents (17a) from being interpreted as involving a structure like (17c); rather it is just pragmatically ill-formed. In a sense, by saying this they admit that the semantics of the predicate is important to constrain which syntactic structure it may be associated with.

17) a. They guillotined Mary.

b. [vP [DP They][v'、 GUILLOTINE [PP=SC [DP Mary] [P' PTCR VGUILLOTINE]]]]

c. \# [vP [DP They] [v' [v VGUILLOTINE v] [DP Mary]]]

(\# on the reading: "They created Mary guillotining/with a guillotine".)

In fact, the semantics of the predicate guillotine provides essential reference for proper syntactic structures to be built. As Kiparsky (1997) notes denomial causative verbs refer to generically intentional activities and if an action is named after a thing, it involves a canonical use of the thing. Thus the verb guillotine derives its prototypical meaning from the canonical use of the thing that it named after, i.e., a piece of machine used to cut off people's head. Only based on this conceptual component of the predicate, may the selection of relevant syntactic structure be possible. Similarly, Rappaport Hovav also observes that even the syntactic approach makes implicit distinction between conceptual and relational notion of manner representing the former as (18a) and the latter as (18b). More essentially, as proposed by Rappaport Hovav and Levin (2010), the semantics of manner and result verbs can be well delineated as scalar and non-scalar changes independently, so it is possible to tease the lexicalized meaning components of verb root out from those contributed by particular contexts.

18) a. [v' [v $\sqrt{\text { SMILE }]}[\sqrt{ }$ SMILE $]]]$

b. [v' [v $\sqrt{ }$ SMILE v] [DP their thanks]]]

Therefore, it can be seen that conceptual knowledge is indispensable in explaining the notions of manner and result, and they cannot be reduced to merely different syntactic configurations.

Rapoport (2012) proposes the MRC derive from differences in aspectual focus rejecting a root view of the MRC proposed by both Rappaport Hovav and Levin as well as by Mateu and Acedo-Matellan. According to her, the minimal semantic unit which determines the syntactic structure that a verb may appear in is not the root; rather a verb may be composed of two different types of atomic meaning components, manner atoms (manners, instruments, means) and result atoms (states, locations), which freely and independently merge syntactic structures with different argument realization patterns and aspectual properties. Variable grammatical behaviors of a verb are all derived from a single lexical entry. A manner or a result atom projecting distinct aspectual features each is associated with only one part of a syntactic structure. When interpreting a structure, only one part of the structure can be foregrounded with the other being backgrounded. The impossibility of foregrounding two parts of a structure simultaneously results in the MRC.

In Rapoport's approach, verbs with variable grammatical behaviors can be explained directly by the free projection of different atomic meaning components into syntactic structures, so it does not have the problem of the proliferation of lexical entries on one hand, and on the other, it also saves the trouble of formulating interface or mapping rules such as template augmentation based on event structures. In a sense, it is theoretically economical and effective in tackling the lexicon and syntax interface. However, there is also an obvious problem with it: free projection of meaning atoms and proposed aspectual focus lead to undergeneralization of verbs which otherwise fall into natural classes based on their ontological type, manner or result. According to Rapoport (2012), based on how verbs are composed up with different types of atomic meaning components, they can be divided into three types: verbs with a manner atom, verbs with a result atom and verbs with both manner and result atoms, as in (19).

19) a. Verbs with a manner atom: run, jump, laugh

b. Verbs with a result atom: arrive, enter, advance, cool, melt

c. Verbs with both manner and result atoms: cut, melt, break, hit

As to verbs with only one type of atomic component either manner (19a) or result (19b), there is no disagreement upon the interpretation of grammatical behaviors of these verbs between Rappaport Hovav and Levin's lexicalist approach and Rapoport's atom theory, since no matter how the meaning unit is named, manner/result atoms or manner/result verb roots, their different grammatical behaviors are basically determined by the meaning components encoded in the lexical entries. The two approaches do show contrast in interpreting grammatical behaviors of verbs which are claimed to have both types of meaning atoms in Rapoport's approach in (19c). It can be seen that these verbs crosscut the ontological types of manner and result verbs in lexicalist approach. Rapoport mainly bases her argument on verbs which show the grammatical behaviors of both manner and result verbs. Generally, she considers the properties of verbs that can appear with constructions or time adverbials which show the durative aspectual feature as hallmarks to indicate they contain manner atoms. According to her, for example, concerning the meaning atoms that the verb cut contains, whereas generally its result atom is focused to indicate a result state of a clear separation in its prototypical uses as in (20a), it is also possible to focus its manner atom when it is used in progressive aspect, with durative time adverbial, or in conative construction in (20b-d). Rapoport explains that in either case both meaning atoms are present,

\footnotetext{
${ }^{1}$ In Hale and Kayser's 2002 sense: A TCR involves a coincidence between one edge or terminus of the theme's path and the place, while a central coincidence relation (CCR) involves a coincidence between the center of the theme and the center of the palce)
} 
but only one can be focused at a time.

20) a. Jane cut the ropes in ten minutes.

b. Jane was cutting the bread for an hour.

c. Jane cut the ropes for ten minutes.

d. Jane cut at the ropes for an hour.

(Rapoport, 2012, pp. 4-9)

Rappaport Hovav and Levin (2013) also address the variable behaviors of the verb cut proposing it lexicalize only one meaning component manner or result in each use with the other one dropping out. Probably, at this stage it is difficult to tell which approach is more tenable.

However, some other verbs which are also claimed to contain both manner and result atoms, such as hit and break, pose a challenge for Rapoport's atom theory, because these verbs never defocus the meaning atom that is assumed to be the lexicalized meaning component in the roots in Rappaport Hovav and Levin's (1998, 2010) approach and alternatively focus the other meaning atom. For instance, Rapoport claims that break contains both a result atom 'being dysfuctional' and a manner atom 'using forceful means' (Rapoport, 2012, p. 2), but in its various uses, the manner atom cannot be focused. Using Rapoport's tests to detect the aspectual focus associated with manner atom, break cannot be used in conative construction as in (21a) and it is incompatible with durative time adverbials as in (21b). Similarly, the verb hit is also assumed to have both a manner atom 'using forceful manner' and a result atom 'being at the point of contacting' (Rapoport, 2012, p. 2), but it does not exhibit the aspectual focus of the result atom, as it is not compatible with framed time adverbial 'in X time' as in (21c). Then if these verbs contain a type of meaning atom which cannot be aspectually focused, how could one possibly know there is indeed such a meaning atom in the semantics of the lexical entries? Rapoport proposes that only the manner atom associated with "wielding of a particular instrument" can be focused (Rapoport, 2012, p. 8), and there is no focusable action associated with "implementing forceful means", but the fact is that though both the verb break and hit are associated with a manner atom "forceful means/manner", the action expressed by hit in (21d) but not by break in (21a) can be focused. Therefore Rapoport's argument that verbs such as break and hit contain two types of meaning atoms are not convincing; rather these facts are better to be understood as these verbs contain only one meaning component result or manner, thus conforming to their ontological categorization suggested by Rappaport Hovav and Levin (1998, 2010). Correspondingly, it is also better to treat verbs like cut as polysemous verbs with different meaning components lexicalized in each use. It is more tenable to regard the MRC as a constraint operating in the lexicon rather than differences in aspectual focus projected from different meaning atoms.

21) a. *Jane broke at the vase.

b. *Jane broke the vase for two minutes

c. * Jane hit the door in a minute.

d. Jane hit at the door.

This section has examined arguments which question the validity of the MRC as a lexical constraint. It reveals that manner and result cannot be reduced to either different syntactic configurations or differences in aspectual focus. A root view of the MRC that manner and result are conceptual notions constrained by verbs' ontological type is supported.

\section{CONCLUSION}

Focusing on the MRC hypothesis, the paper reviews the lexicalist approach to lexicon-syntax interface and the theoretical framework related to the MRC has been explicated by introducing the theoretical motivation for the MRC hypothesis, semantic notions of the manner and result verbs. Manner of killing verbs in English, which are proposed to constitute counterexample verbs to the MRC are discussed and demonstrated that they actually lexicalize only the meaning component of result but not manner and thus do not undermine the validity of the MRC. Two approaches which observe the linguistic phenomena corresponding to the MRC but deny its status as a lexical constraint are also reviewed and shown that the MRC cannot be understood as only deriving from different syntactic configurations or merely differences in aspectual focus. Rather it is a viable principle operating in the lexicon.

\section{REFERENCES}

[1] Acedo-Matellán, V. and J. Mateu. (2010). From syntax to roots: A syntactic approach to root ontologies (ms.). Paper presented at Roots. Word formation from the Perspective of Core Lexical Elements. University of Stuttgart. June 10-12 2009.

[2] Aldridge, L. E. (2012). What's in a Verb? Evidence from Manner/Result Complementarity, Undergraduate Thesis. University College London.

[3] Beavers, J., B. Levin, and S. W. Tham. (2010). A morphosyntactic basis for variation in the encoding of motion events. Journal of Linguistics, 46: 331-377.

[4] Beavers, J. and A. Koontz-Garboden. (2012). Manner and result in the roots of verbal meaning. Linguistic Inquiry 43(3): 331-369.

[5] Erteschik-Shir, N. and T. Rapoport. (2010). Contact and other results. In M. Rappaport Hovav, E. Doron, and I. Sichel (eds.) Lexical Semantics, Syntax, and Event Structure, 59-75. Oxford: Oxford University Press.

[6] Goldberg, A. E. (2010). Verbs, constructions, and semantic frames, In E. Doron, M. Rappaport Hovav, and I. Sichel (eds.), Syntax Lexical Semantics, and Event Structure, Oxford, UK: Oxford University Press. 
[7] Husband, E. M. (2011). Rescuing manner/result complementarity from certain death, Proceedings of the 47th Annual Chicago Linguistics Society.

[8] Jackendoff, R. (1997). The Architecture of the Language Faculty. Cambridge, MA: MIT Press.

[9] Kennedy, C. (2001). Polar opposition and the ontology of "degrees". Linguistics and Philosophy, 24: 33-70.

[10] Kennedy, C. and L. McNally. (2005). Scale structure and the semantic typology of gradable predicates. Language, 81(2): 345-38.

[11] Kiparsky, P. (1997). Remarks on Denominal Verbs. In A. Alsina, J. Bresnan and P. Sells (eds.), Complex Predicates, $473-499$. Stanford: CSLI Publications.

[12] Levin, B. and M. Rappaport Hovav. (2013). Lexicalized meaning and manner/result complementarity, in B. Arsenijević, B. Gehrke, and R. Marín (eds.), Studies in Composition and Decomposition of Event Predicates, 49-70. Dordrecht: Springer.

[13] Mateu, J. and V. Acedo-Matell'an. (2012). The manner/result complementarity revisited: A syntactic approach, in M.C. Cuervo and Y. Roberge, (eds.), The End of Argument Structure, 209-228. Bingley: Emerald.

[14] Neeleman, A. and H. van de Koot. (2010). The linguistic expression of causation, In Working Papers in Linguistics, 78-100. University College London.

[15] Rappaport Hovav, M. (2015). Towards an understanding of the notions of 'manner' and 'result' and their role in the construction of verb meaning. In Roots Worshop, The Hebrew University of Jerusalem.

[16] Rappaport Hovav, M., and B. Levin. (1998). Building verb meanings. In M. Butt and W. Heuder (eds.), The Projection of Arguments: Lexical and Compositional factors, 97-134. Stanford, CA: CSLI Publications.

[17] Rappaport Hovav, M., and B. Levin. (2010). Reflections on manner/result complementarity. In E. Doron, M. Rappaport Hovav and I. Sichel (eds.), In Syntax, Lexical Semantics, and Event structure, 21-38. Oxford: Oxford University Press.

[18] Rapoport, T. (2012). Abandoning manner-result complementarity. Around the Verb Workshop. University of Paris III: Sorbonne Nouvelle, September 2012.

Lei Qiu was born in Shandong, China. She received her master's degree in linguistics and applied linguistics at Northeastern University, China in 2007. She received her doctoral degree in international cultural studies at Tohoku University, Japan in 2017. Now she is an EFL teacher at the School of Foreign Languages, Huaiyin Normal University. Her academic interests include lexical semantics and cognitive semantics. 